\title{
¿POR QUÉ IMPORTA LA FILOSOFÍA EN LA EDUCACIÓN ESCOLAR DEL SIGLO XXI?
}

\author{
¿POR QUÉ IMPORTA LA FILOSOFÍA EN \\ EL CURRÍCULUM ESCOLAR? ${ }^{1}$
}

\author{
Sylvia Eyzaguirre Tafra \\ Centro de Estudios Públicos \\ seyzaguirre@cepchile.cl
}

Esta presentación es de un orden radicalmente distinto al de la presentación de Carlos Peña, porque no es filosófica; consiste más bien en pensar qué papel puede jugar la filosofía en la formación del ciudadano y, como ustedes saben, las democracias modernas en verdad requieren, como condición de posibilidad para la constitución política de la democracia, ciudadanos, que tienen que tener ciertas competencias, ciertos conocimientos, y a eso responde justamente la escuela, la formación obligatoria escolar -la cual, como ustedes saben, en Chile llega hasta los 18 años; en otras partes del mundo, hasta los 16 o los 14 años.

Entonces, en las democracias modernas, donde los individuos tienen que ser autorregulados, pues de ellos depende el régimen político, la pregunta es ¿qué características tiene que tener esta formación para que podamos tener democracia? Y en relación con esa pregunta ¿qué rol le cabría a algo así como la filosofía? No me refiero a la filosofía entendida, como en Heidegger, como una posibilidad del ser humano y una posibilidad muy singular; es decir, no me refiero a la filosofía entendida como esa posibilidad radical teórica y ontológica del ser humano, que es una respuesta a sus inquietudes ónticas, sino a una filosofía que tiene que ver, justamente, con despertar estas preguntas ónticas, que constituyen, a su vez, la condición de posibilidad para que pueda haber algo así como filosofía en la escuela.

Entonces, trataré de hacer tres argumentaciones [distinciones] de por qué considero importante la formación de filosofía en la escuela a partir de la edad temprana. La primera tiene que ver con una consideración netamente utilitarista y basada en evidencia empírica. Como saben, en el siglo XXI los avances de la tecnología nos enfrentan a desafíos inconmensurable. Se cree que en 15 o 10 años más cerca del 50\% de los empleos que hoy día conocemos van a ser tecnologizados y reemplazados por robots; la medicina completa va a ser revolucionada a una medicina genética individual, que nos va a llevar a preguntarnos por el quehacer propio del ser humano en la tierra. Ante un futuro tan desconocido ¿cómo formar a las futuras generaciones para que puedan 
enfrentar ese futuro? Entonces la pregunta es ¿cómo vamos a formar a estas futuras generaciones para enfrentar un futuro que no conocemos, para enfrentar un mundo que no sabemos cómo va a ser salvo que va a ser radicalmente distinto al que hoy día existe.

Hay entre los expertos relativo consenso en torno a cuáles son las habilidades que estas generaciones tienen que desarrollar para poder enfrentar la ambigüedad, la incertidumbre del futuro. Una de esas habilidades, que es crucial, tiene que ver con razonamiento crítico, con pensamiento crítico. Pensamiento crítico, en fácil, es saber pensar. Pensamiento crítico es razonamiento crítico, saber pensar. Uno puede decir que, por supuesto, parte importante de lo que tenemos que aprender en la escuela, y después en la educación superior, es aprender a pensar. Sin embargo, desde mi experiencia personal, yo diría que esta es una experiencia relativamente escasa. Y ¿por qué la filosofía, entonces, puede servir y ser funcional a esta experiencia del pensar? Por lo que es propiamente la filosofía. En efecto, uno de los aspectos que quiero recalcar, aunque sea brevemente, es la importancia del razonamiento crítico y cómo la filosofía es una disciplina que tiene características particulares por las que puede ayudar al desarrollo de esta habilidad. Yo creo que la historia bien realizada, la reflexión histórica, la reflexión literaria son instrumentos que también pueden ser muy funcionales al desarrollo de la capacidad y del pensamiento crítico. Pero la filosofía tiene algo que no tienen las demás disciplinas, y que es preguntarse por la condición de posibilidad de la ciencia en cuanto tal. Es decir, la filosofía reflexiona sobre la condición de posibilidad de la reflexión literaria, de la reflexión estética, de la reflexión histórica; reflexiona acerca de cuáles son los supuestos sobre los cuales se están construyendo estas disciplinas y qué tipo de conocimiento nos entregan estas propias disciplinas, una reflexión que no pueden hacer ellas mismas, porque, si lo hacen, ya se vuelven a una reflexión que es propia de la filosofía.

Entonces, la filosofía tiene esta característica de no solamente poder abordar el conocimento en cuanto tal, sino poder abordar la estructura del conocimiento, su arquitectónica; ponerlo delante -hacerlo objetivo-y hacerlo comprensible, y sacar a luz cuáles son sus supuestos, las condiciones de posibilidad de esos supuestos así como las conclusiones y las concatenaciones lógicas que permiten desarrollar de forma mucho más rigurosa y lúcida las capacidades críticas del pensamiento.

No solamente tiene esta capacidad hermenéutica y analítica para pensar fenómenos, sino que, además, en ese pensamiento del fenómeno y en esa dilucidación del fenómeno, ella también saca a la luz la propia estructura de ese pensamiento, lo cual es algo muy propio de la filosofía y que no veo que suceda en otras disciplinas. Y cuando esas disciplinas hacen dicha reflexión, entonces pasan a hacer filosofía: hacen filosofía de la historia, hacen estética propiamente tal, hacen filosofía de la música. Y justamente el razonamiento crítico tiene que ver con poder reconocer estructuras de pensamiento, y entender no solamente lo que se está diciendo, sino cómo se está diciendo, cuáles son sus supuestos y condiciones de posibilidad. En todo eso creo que la filosofía tiene una ventaja enorme respecto de las otras disciplinas. Reflexionando sobre los problemas filosóficos es como mejor se puede ir aprendiendo y adquiriendo esas habilidades analíticas, hermenéuticas y críticas, que son, según los expertos, 
fundamentales para la formación de ciudadanos democráticos y que sepan hacer frente a un mundo absolutamente incierto.

Esta dimensión de la filosofía, la dimensión utilitarista, está avalada por evidencia empírica. Hay distintos experimentos que se han hecho en el mundo, donde se introduce la asignatura de filosofía a niños desde temprana edad con las mismas profesoras que tienen ordinariamente -para que sea realmente experimental-, y luego, al cabo del primer año así como al cabo del segundo año, evalúan sus avances en comparación con los otros niños de esas mismas profesoras, que no han tenido la asignatura de filosofía. Los resultados arrojan que los niños tienen un desarrollo muy superior en lenguaje, en capacidad de abstracción e incluso en matemáticas, en comparación con los otros niños que no estuvieron expuestos a esta forma de abordar el pensamiento y las reflexiones. Y además manifiestan el desarrollo de habilidades blandas, como mayor autoestima, mayor capacidad de escucha, y capacidad de diálogo y argumentación. Esta es una dimensión de la filosofía que yo considero que es muy importante considerar a la hora de armar un currículo nacional, para desarrollar estas habilidades en los futuros ciudadanos.

Otro valor de la filosofía, que yo creo que es importante más allá de las habilidades cognitivas antedichas, tiene que ver con una función política fundamental: la filosofía es la condición de posibilidad de la democracia. En efecto, para que haya democracia tiene que haber ciudadano y ¿qué es un ciudadano? Es una persona crítica, autónoma, con capacidad de decidir sus propios gobiernos y tener él mismo las condiciones necesarias para poder gobernar. La democracia exige, entonces, personas libres y autónomas que puedan distinguir algo tan básico como el bien del mal. Es decir, tienen que ser personas críticas y con capacidad de reflexión ética, lo cual es algo absolutamente clave en la formación ciudadana y en la participación de las democracias modernas. Ahora bien, para formar seres éticos tenemos que poder distinguir entre el bien y el mal, y esa distinción podemos heredarla de la religión o de la política-las orientaciones políticas también nos entregan criterios de distinción-, pero la filosofía es la única disciplina que nos va a hacer enteramente libres y nos libera de esos otros criterios que, de alguna manera, han sido heredados. Únicamente la filosofía nos entrega la capacidad para que podamos crear nuestros propios criterios fundados en una reflexión racional. Y es en ese ámbito de crear ciudadanos críticos y sujetos morales autónomos que la filosofía cumple una función fundamental e imprescindible.

En tercer lugar, en la escuela tenemos que desarrollar no solamente un rol político (que es también económico), sino que la formación tiene que ver sobre todo con la formación del ser humano como persona. La filosofía cumple también la función del desarrollo de la persona. Pero a mí no me gusta vincular este desarrollo directamente con la escuela, porque la formación, la educación en sentido amplio es el proceso de transformación del individuo, y este proceso - lo que llamamos la educación- ocurre fuera y dentro de la escuela: ocurre en la familia, ocurre en los medios de comunicación, ocurre en las bibliotecas, ocurre jugando, etc. La escuela es solo un ámbito particular de este proceso 
de formación; pero es un espacio democrático donde hemos consensuado qué tipo de desarrollo se requiere para ser ciudadanos, mientras que otros espacios lo hemos dejado al arbitrio de las familias: así lo que tiene que ver con la religión y con el desarrollo más artístico y demás formas de despliegue de los individuos. Pero no cabe duda de que parte del desarrollo de la persona tiene que ver con ser una persona libre, una persona autónoma, y eso exige una persona que se haga preguntas (pues una persona que es autónoma es un ser que tiene preguntas). Pero formar para hacerse preguntas es incentivar la curiosidad, y ésta es la condición de posibilidad para que haya algo así como conocimiento, algo así como ciencia. En efecto, si uno estudia una ciencia, si uno estudia física, química o filosofía o historia y no tiene preguntas, eso no nos sirve, eso no es auténtico, eso no tiene sentido. De alguna forma, es un mero repetir, que no está enraizado en lo más profundo del ser humano. Al respecto, creo que la filosofía también cumple una función fundamental, que es el despertar la curiosidad. El origen de la filosofía es la curiosidad, decía Aristóteles, y el saber surge de una curiosidad muy particular con respecto a determinadas preguntas que tienen que ver, al final del día, con quién soy yo y cuál es el sentido de mi existencia, para qué estoy yo en este mundo.

Si bien la educación en Chile ha dejado fuera estas preguntas como parte de la formación que le tenemos que entregar a nuestros niños para hacerlos ciudadanos, yo creo que es una parte fundamental, porque esa parte es la que nos hace ser humanos. Es en la reflexión crítica respecto de lo que somos nosotros mismos donde podemos cultivar algo así como una humanidad, lo cual creo que es fundamental y esencial para el sentido del ciudadano en las democracias modernas. Eso hoy día no está consensuado políticamente y lo estamos dejando fuera de la formación que entregamos en las escuelas; creo que es fundamental incorporarlo, para atender a esa otra dimensión de la formación de un ciudadano en la democracia.

Entonces veo estas tres como funciones que podría tener la filosofía, o "utilidades" que podría tener la filosofía. La primera, que tiene que ver con la dimensión utilitarista, que tiene que ver con desarrollar estas capacidades críticas en los individuos. Una segunda, que tiene que ver con formar seres morales, que son fundamentales, porque son condición de posibilidad para las democracias, que son seres autónomos, a diferencia de las monarquías, por ejemplo, u otros estados jerárquicos. Y la tercera tiene que ver con el desarrollo y el cultivo de la humanidad, pero de la humanidad en sentido existencialista, como ¿quién soy?, ¿para qué estoy acá?, ¿cuál es el sentido?, porque solo a partir del establecimiento de esas preguntas de alguna manera puedo ejercer también las otras preguntas de forma auténtica, es decir, las preguntas que surgen de las ciencias, preguntas que surgen de la medicina, las preguntas que surgen de otras áreas, que, en última instancia, también están relacionadas con mi propia existencia.

Y por último, solamente una reflexión: los avances de la tecnología que van a venir son tan abrumadores que van a poner en crisis todo el conocimiento. Hoy día tenemos una definición más o menos consensuada de lo que entendemos por ser humano, a pesar de que cuando queremos definirlo probablemente no vamos a estar completamente de acuerdo. Pero todos entendemos lo que es el ser humano, todos entendemos qué son 
los seres con vida, todos entendemos lo que es el tiempo, el espacio, y, sin embargo, la ciencia nos va a poner en crisis lo que son los seres humanos: hoy día estamos creando seres humanos con un material genético de dos mujeres, sin hombres; hoy día estamos creando seres humanos manipulados genéticamente, que podrían llegar, el día de mañana, a ser eternos. ¿Cambia la esencia del ser humano el hecho de que ya no puedan ser susceptibles de la muerte? Es decir, van a entrar en crisis los conceptos que estamos teniendo respecto de lo que es vida, de lo que es materia y de lo que es un ser humano, y se requiere, por lo tanto, una redefinición de estos conceptos. Y los avances científicos y tecnológicos van a poner en crisis también la ética. La ética que tenemos hoy día respecto del bien y el mal es una ética que está hecha a partir del paradigma de la finitud, de la mortalidad. Un ser que ya deja de ser finito ¿requiere o no otra ética, requiere o no otro paradigma ético, para poder seguir existiendo? Yo creo que los avances en tecnología nos van a llevar a un tal punto -y cerca, y pronto-, que podrían llegar a exigir una nueva ontología; y ahí, por supuesto, que eso es probablemente tarea de la filosofía, volver a pensar cómo se manifiesta el ser en este nuevo mundo, que todavía no conocemos, pero que estamos al borde de experimentar. 